\title{
Biomechanische aspecten met betrekking tot hoefbeslag bij paarden
}

\author{
Biomechanical aspects of farriery in horses
}

\section{Oosterlinck, M. Dumoulin, E. Van de Water, F. Pille}

Vakgroep Heelkunde en Anesthesie van de Huisdieren, Faculteit Diergeneeskunde, Universiteit Gent, Salisburylaan 133, B-9820 Merelbeke

Maarten.Oosterlinck@UGent.be

\section{AMENVATTING}

In dit artikel wordt een overzicht gegeven van de huidige biomechanische inzichten die nuttige aanwijzingen kunnen verschaffen voor "evidence-based" keuzes omtrent het bekappen en/of het aanbrengen van hoefbeslag in de behandeling van kreupelheid bij het paard. De nadruk wordt gelegd op een optimale hoefbalans, de absorptie van schokken, de gepaste mate van grip/afremmen versus glijden, optimale drukverdeling binnen de hoef, en het bevorderen van "breakover". Ook met het hoefmechanisme moet rekening gehouden worden. Ideaal gezien worden de meeste van deze principes reeds gecombineerd in de preventie van letsels.

\section{ABSTRACT}

In this paper, the current biomechanical concepts that are important for the evidence-based application of trimming and shoeing techniques in the treatment of lameness in horses are reviewed. Hoof balance, shock absorption, grip versus sliding of the hoof, the pressure distribution within the hoof and hoof breakover are discussed. Moreover, possible effects on the hoof mechanism should be taken into account. Ideally, these issues should be considered in the prevention of injury rather than in the treatment of established pathology.

\section{INLEIDING}

Het onderzoek en de behandeling van kreupelheid vormen van oudsher een van de belangrijkste taken van dierenartsen. Voor talloze problemen aan het bewegingsstelsel van het paard zijn er verschillende medicamenteuze en chirurgische behandelingen beschreven. Het mogelijke therapeutische belang van het bekappen van hoeven en het aanbrengen van een aangepast hoefbeslag wordt echter nog vaak onderschat. Gezien het verband tussen de uitwendige vorm van het hoefkapsel en de functionele belasting van inwendige structuren, is het de bedoeling om met het bekappen en het eventuele aanbrengen van hoefbeslag de functie van de hoef en de belasting op anatomische structuren te optimaliseren. Dit kan bijdragen tot de preventie van letsels op bepaalde predilectieplaatsen, maar kan ook nuttig zijn in de behandeling van een reeds bestaande pathologie.

Gedurende eeuwen was hoefsmederij een ambacht gebaseerd op tradities, persoonlijke ervaring en empirische gegevens (Eliashar, 2007). De laatste jaren wordt er echter meer en meer onderzoek uitgevoerd omtrent de biomechanica van de hoef en de beweging van het paard en geleidelijk komt er wetenschappelijk onderbouwde informatie over specifieke technieken voor het bekappen of beslaan van hoeven ter beschikking. Er kan dan ook verondersteld worden dat de technologische vooruitgang uiteindelijk de paardendierenarts en hoefsmid zal kunnen voorzien van objectieve en kwantitatieve meetinstrumenten die routinematig gebruikt kunnen worden om de beweging van het paard en technieken uit de hoefsmederij te beoordelen (Roepstorff, 2012). In dit opzicht biedt bijvoorbeeld een drukplaat met een hoge dichtheid aan sensoren en een hoge meetfrequentie unieke perspectieven om de symmetrie van de belasting van de ledematen te beoordelen, het contactoppervlak van de hoef met de bodem te beoordelen, de drukverdeling onder de hoef te bestuderen en om de teen-hiel en mediolaterale hoefbalans van de verticale kracht te analyseren, zelfs op een zandbodem (Oosterlinck et al., 2010; 2011; 2012; 2013; 2014; Oomen et al., 2012). Dit biedt mogelijkheden om subtiele afwijkingen in hoefbalans op te sporen bij paarden met een abnormale hoefconformatie (Oosterlinck et al., 2015). 


\section{BIOMECHANICA}

Inzicht in de belasting van de ledematen en de hoef-bodeminteractie is van fundamenteel belang om een gefundeerde keuze te maken tussen de verschillende technieken qua bekappen van hoeven en hoefbeslag. In dit artikel wordt een overzicht gegeven van de biomechanische aspecten van hoefbelasting. De kracht die een hoef op de bodem uitoefent gedurende de steunfase, kan onderverdeeld worden in drie componenten: in verticale richting $(\mathrm{Fz})$, in craniocaudale richting (Fy) en in mediolaterale richting (Fx) (Oosterlinck et al., 2007) (Figuur 1). De totale duur van de steunfase is ongeveer 700-800 ms in stap en 300$400 \mathrm{~ms}$ in draf. De verticale kracht heeft de grootste amplitude. Ter hoogte van het voorbeen bedraagt ze ongeveer $60 \%$ van het lichaamsgewicht in stap, 90\% van het lichaamsgewicht in draf aan lage snelheid en zelfs meer wanneer de snelheid toeneemt of bijvoorbeeld tijdens het springen of landen. In stap vertoont de verticale kracht meestal een bifasisch verloop, waarbij ter hoogte van het voorbeen de tweede piek meestal een hogere amplitude vertoont dan de eerste piek en vice versa in het achterbeen (Figuur 2A). In draf wordt een eerste piek gezien na impact gevolgd door een geleidelijke stijging tot een maximum halverwege de steunfase en tenslotte een geleidelijke daling tot het einde van de steunfase (Figuur 2B). De craniocaudale kracht is initieel een remmende kracht, grafisch weergegeven door het gedeelte van de curve dat zich onder de horizontale as bevindt. In het tweede deel van de steunfase wordt deze kracht voortstuwend, geillustreerd door het gedeelte van de curve dat zich boven de horizontale as bevindt. De mediolaterale kracht heeft een zeer kleine amplitude en vertoont een vrij grote interindividuele variatie.

De steunfase kan onderverdeeld worden in verscheidene fasen met sterk verschillende biomechanische kenmerken (Thomason en Peterson, 2008; Back en Pille, 2013):

1. De impactfase vertegenwoordigt het initiële contact van de hoef met de bodem, gewoonlijk met de laterale hiel; dit valt niet met het blote oog waar te nemen. Deze eerste fase kan onderverdeeld worden in een primaire impactfase, waarmee het allereerste contact met de bodem bedoeld wordt. Dit wordt gekenmerkt door een enorme afremmende kracht in verticale richting (tot $400 \mathrm{~g}$ ) (Gustas et al., 2006) en daaropvolgende uitgesproken vibraties maar lage krachten die inwerken op het lidmaat. Vervolgens wordt de secundaire impactfase onderscheiden, waarbij de verticale kracht toeneemt terwijl de hoef in horizontale richting afgeremd wordt (tot $200 \mathrm{~g}$ ) (Gustas et al., 2006) totdat ze stevig op de bodem staat.

2. Gedurende het middelste deel van de steunfase bereikt de verticale kracht een maximum (tot 2,5 keer het lichaamsgewicht).

3. Uiteindelijk neemt de verticale kracht geleidelijk af. Wanneer de hielen de bodem verlaten, begint

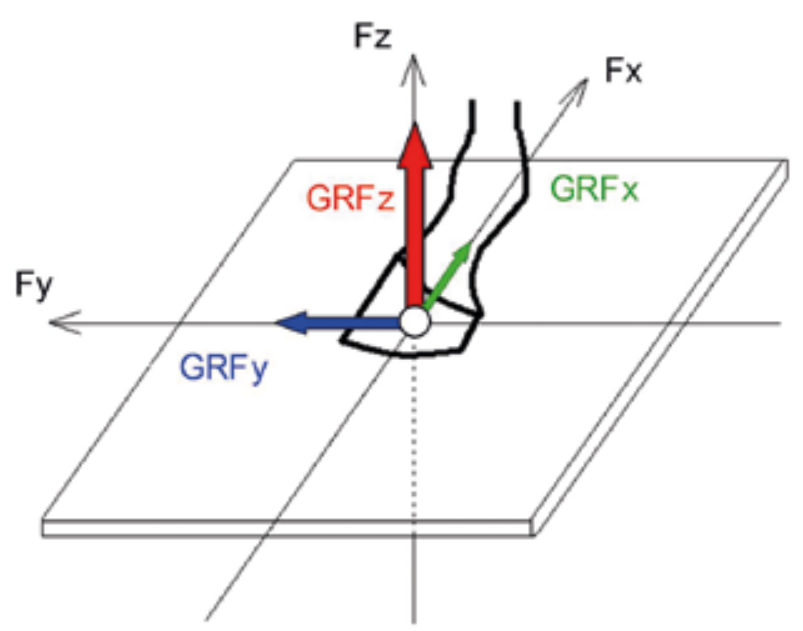

Figuur 1. Krachten die door een hoef uitgeoefend worden op de bodem. De zogenaamde grondreactiekracht ("ground reaction force" (GRF)) wordt onderverdeeld in drie orthogonale componenten $(\mathrm{Fx}, \mathrm{Fy}, \mathrm{Fz})$ (Oosterlinck et al., 2007).

A

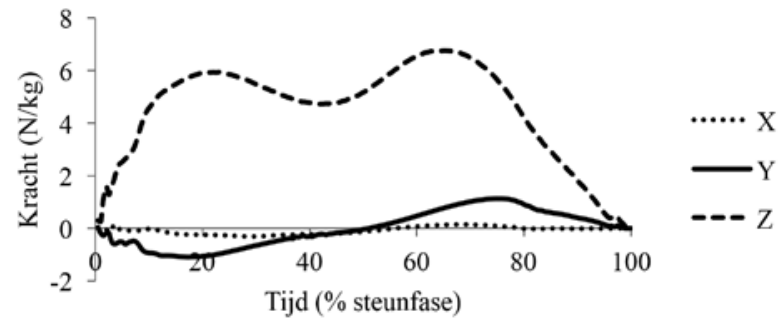

B

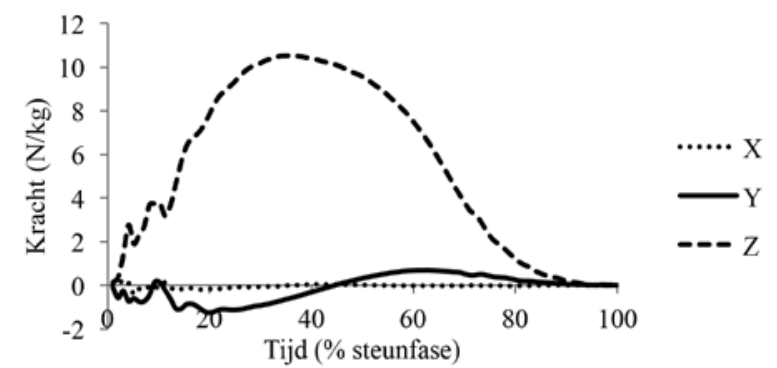

Figuur 2. De mediolaterale $(\mathrm{X})$, craniocaudale $(\mathrm{Y})$ en verticale $(Z)$ componenten van de grondreactiekracht (GRF; N/kg) van het voorbeen in functie van de tijd (\% steunfase) A. in stap en B. in draf.

de zogenaamde "breakover"-fase, resulterend in een voorwaartse rotatie van de hoef.

Door de verdeling van de lichaamsmassa over het lichaam van het paard zijn de uitgeoefende verticale krachten ter hoogte van de voorbenen groter dan ter hoogte van de achterbenen. Bovendien worden de voorbenen met een hogere verticale snelheid neergezet terwijl de achterbenen met een hogere horizontale snelheid bewegen; voorbenen vertonen een eerder 'stuiterende' beweging terwijl achterbenen eerder 'glijdend' bewegen (Back et al., 1995).

Alle krachten die optreden tussen de hoef en de bodem kunnen samengevat worden in één enkele 


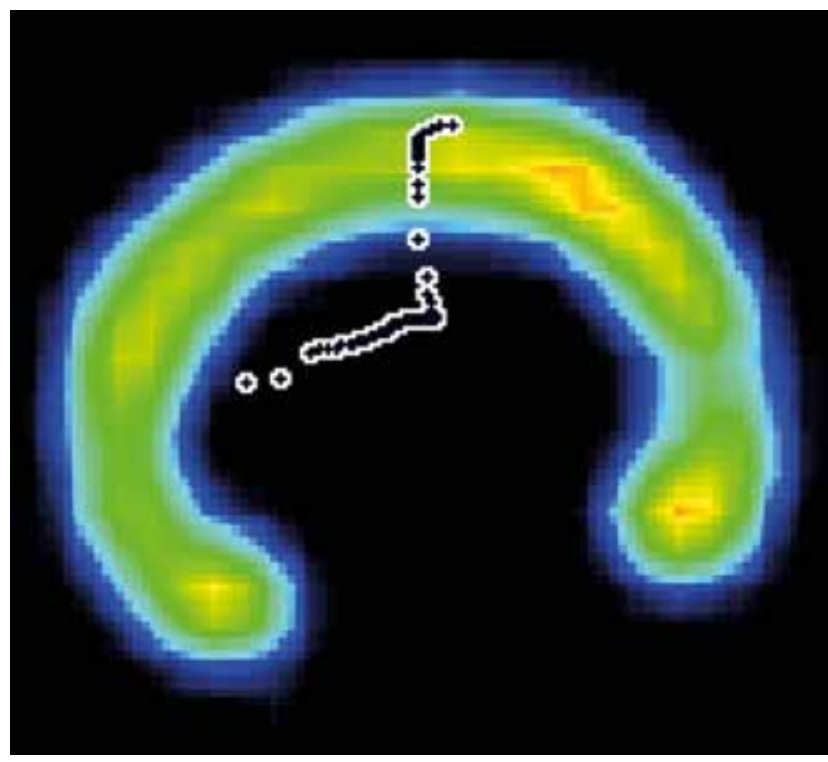

Figuur 3. Linkervoorhoef van een pony in stap op een 2m-drukplaat (RSscan International, Paal, België). De uitgeoefende druk wordt weergegeven volgens een kleurcode (blauw: lage druk, rood: hoge druk) en het verloop van het drukcentrum ("center of pressure") wordt weergegeven door de zwarte kruisjes.

vector. Het aangrijpingspunt van deze vector is het zogenaamde drukcentrum ("center of pressure"). Dit drukcentrum bevindt zich initieel ter hoogte van het eerste contact tussen de hoef en de bodem, maar beweegt vervolgens snel naar het centrum van de hoef, waar het gedurende het grootste deel van de steunfase blijft, alvorens finaal in de richting van de teen op te schuiven (Figuur 3).
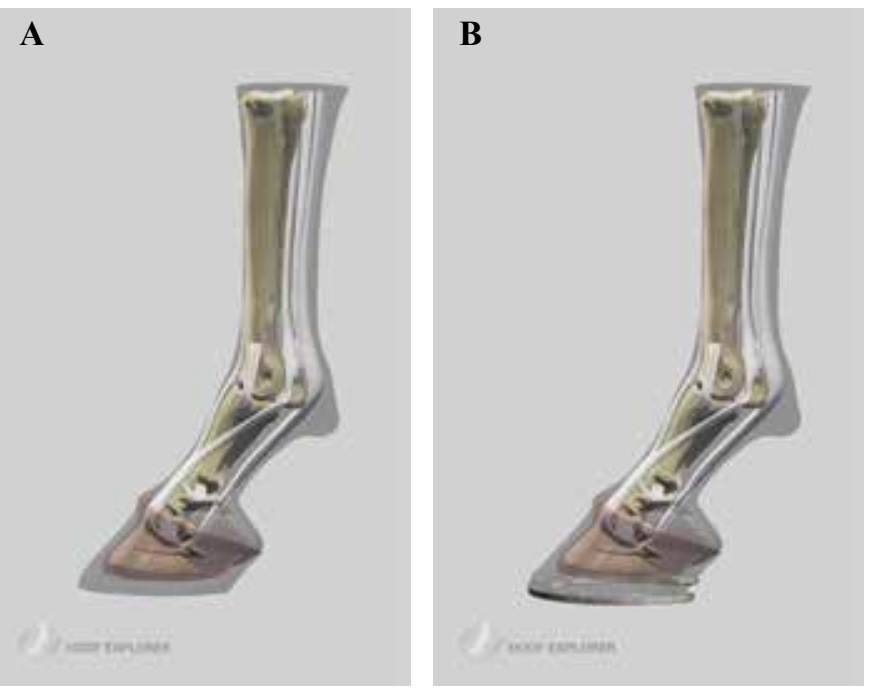

Willemen et al. (1999) toonden aan dat een standaard, vlak hoefbeslag resulteert in $14 \%$ hogere krachten ter hoogte van het straalbeen dan onbeslagen hoeven. Het louter aanbrengen van een standaard beslag impliceert dus reeds een belangrijke biomechanische verandering die weloverwogen dient te gebeuren.

Wilson et al. (1998) hebben aangetoond dat het gebruik van een wigje onder een hoef voor een verschuiving van het drukcentrum in de richting van de ophoging zorgt. Op gelijkaardige wijze werd aangetoond dat bij toepassing van een "egg-bar"-ijzer het drukcentrum naar de palmaire zijde van de hoef verschuift (Rogers en Back, 2007). Bovendien beïnvloeden hoefwiggen en egg-bar-ijzers de hoeken ter hoogte van de gewrichten van het distale deel van het lidmaat (Degueurce et al., 2001; Chateau et al., 2004, 2006a, 2006b). Daarnaast is er ook een effect op de krachten die inwerken op de buigpezen: een verhoging ter hoogte van de hielen zorgt voor een daling van de spanning in de diepe buigpees, terwijl een verhoging ter hoogte van de teen (of een verlaging van de hielhoogte) een stijging in de spanning van de diepe buigpees bewerkstelligt; omgekeerde effecten worden waargenomen in de oppervlakkige buigpees en de $\mathrm{m}$. interosseus medius (Lawson et al., 2007).

Het is belangrijk om te beseffen dat het drukcentrum een dynamisch concept is en dat de evaluatie van eender welke manier van bekappen of beslag niet beperkt mag worden tot een statische beoordeling. Een tweede belangrijke opmerking is dat vele wetenschappelijke studies beperkt zijn tot het evalueren van hoefbeslag op een harde bodem, in tegenstelling tot de zachte, veerkrachtige, vervormbare bodem waar
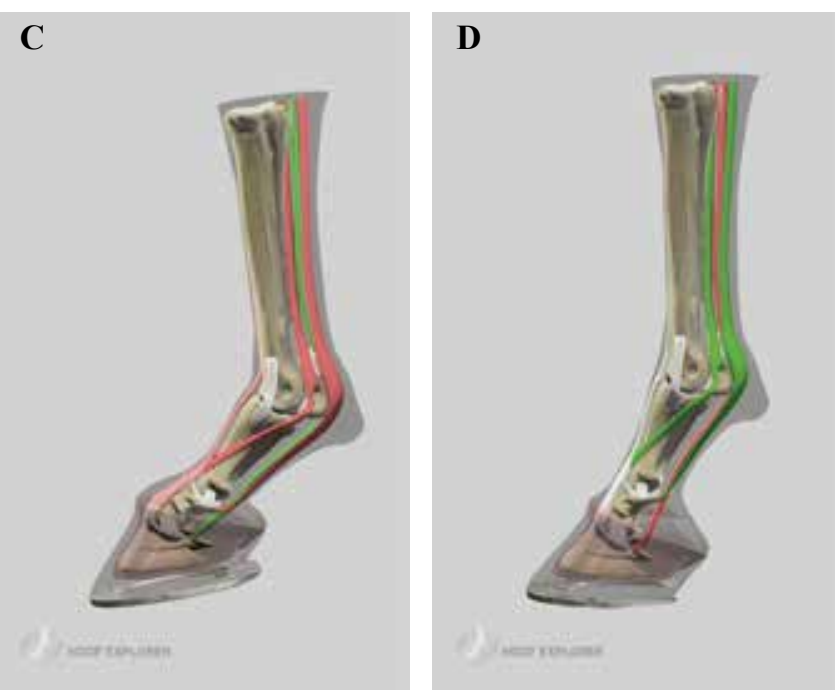

Figuur 4A. Figuur van het distale deel van het lidmaat (zijdelings bekeken) met een onbeslagen hoef. B. Een standaard hoefbeslag induceert geen veranderingen in de spanning van de $\mathbf{m}$. interosseus medius, diepe buigpees en oppervlakkige buigpees. $\mathrm{C}$. Bij een verhoging van de hielen of het verhinderen van het wegzakken van de hielen ten opzichte van de teen door middel van een egg-bar wordt een hogere spanning in de oppervlakkige buigpees en $\mathrm{m}$. interosseus medius waargenomen (rood), terwijl de spanning op de diepe buigpees daalt (groen). D. Bij een verhoging ter hoogte van de teen of het verhinderen van het wegzakken van de teen ten opzichte van de hielen door middel van een bredere teen en smallere takken wordt echter een hogere spanning in de diepe buigpees gezien (rood), terwijl de m. interosseus medius en de oppervlakkige buigpees minder te verwerken krijgen (groen). (Beeldmateriaal uit Hoofexplorer.com met toestemming van Effigos AG, Deutscher Platz 4, 04103 Leipzig, Duitsland). 


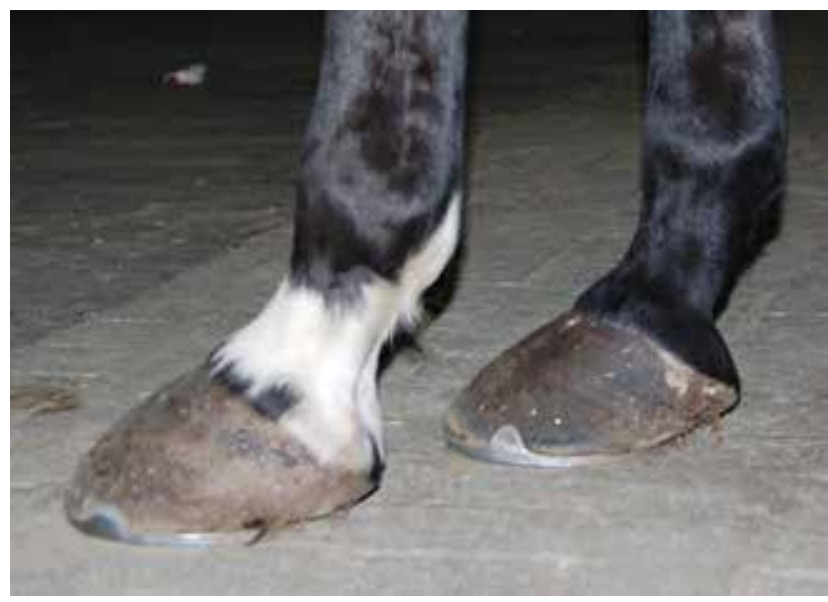

Figuur 5. Zijaanzicht van hoeven met ondergeschoven verzenen, een lange teen en een uitgesproken achterwaarts gebroken hoefkootas.

paarden meestal op gebruikt worden. Het gebruik van een vervormbare bodem heeft belangrijke consequenties (Hagen et al., 2016; Hüppler et al., 2016; Hagen et al., 2017). Zo kunnen egg-bar-ijzers bijvoorbeeld het wegzakken van de hielen in een zandbodem beperken (Chateau et al., 2006a) en aldus het biomechanisch effect nabootsen dat een hielwig op een harde bodem zou hebben. Een belangrijk nadeel van een hielwig is dat dit op lange termijn resulteert in progressieve vervorming van de hielen, wat men probeert te vermijden met een kunststoffen zooltje en opvulling van de ruimte tussen de hoef en het zooltje met siliconen. Een hoefijzer met een bredere teen en smallere takken kan op zijn beurt het wegzakken van de teen in een zachte bodem beperken of aldus het biomechanisch effect nabootsen dat een verlaging van de hielhoogte zou veroorzaken (Figuur 4).

De beoordeling van de hoefbalans is essentieel tijdens het kreupelheidsonderzoek. Het begrip hoefbalans omvat niet alleen de statische, structurele geometrie van de hoef, maar ook de dynamische interactie tussen de hoef en de bodem (Parks, 2003; Johnston en Back, 2006). Hoefbalans en hoefconformatie zijn geen synoniemen maar zijn wel nauw met elkaar verbonden, aangezien een slechte hoefconformatie kan leiden tot een gebrekkige hoefbalans en een slechte hoefbalans ervoor kan zorgen dat een paard een abnormale stand aanneemt, net alsof het een slechte conformatie heeft (Parks, 2011a). Conformatie kan strikt genomen niet meer veranderen zodra het skelet volgroeid is, maar de vorm van het hoefkapsel kan veranderen in functie van de belasting, waardoor finaal de hoefbalans gewijzigd wordt (Parks, 2003). De bespreking van de mogelijkheden tot correctie van conformatiegebreken die bij veulens aangetroffen worden, zoals valgus- en varusdeviaties (Martens et al., 2008), valt buiten het bestek van dit artikel.

De hoefbalans wordt traditioneel geëvalueerd door middel van een visuele beoordeling van de hoef in stilstand en in beweging, zowel in zijdelingse als in voor-achterwaartse richting. Zijdelingse hoefbalans

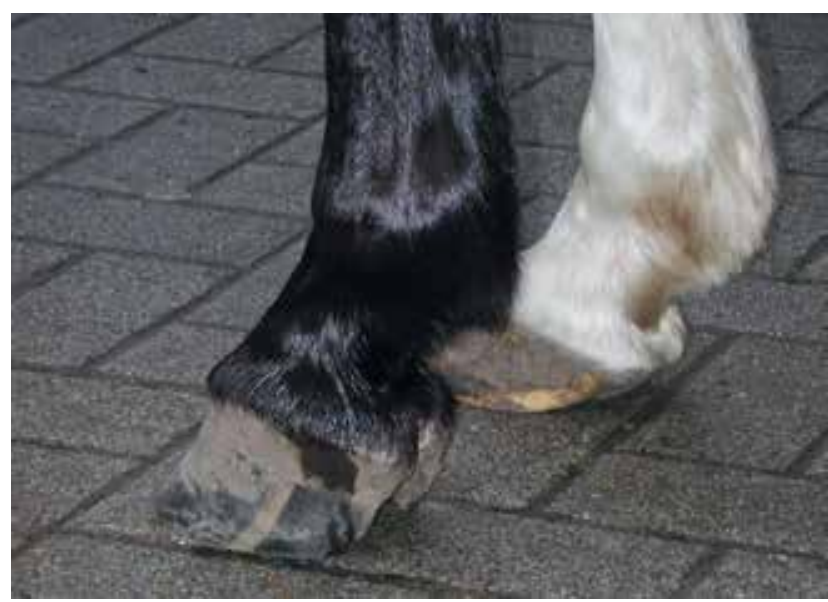

Figuur 6. Zijaanzicht van sterk asymmetrische voorhoeven met een voorwaarts gebroken hoefkootas en hoge hielen ter hoogte van de linkerhoef.

verwijst naar het verband tussen de mediale en laterale zijde van de hoef en naar het landings- en afrolpatroon van het mediale en laterale deel van de hoef. Voor-achterwaartse hoefbalans verwijst naar de hoek die de hoef maakt met de bodem, de verhouding tussen de teen- en de hielhoek en het landings- en afrolpatroon van de teen en hielregio. Een rechte hoefkootas veroorzaakt het minste stress voor de hoef en de inwendige structuren. Een achter- of voorwaarts gebroken hoefkoot-as heeft rechtstreekse gevolgen voor de weke delen (voornamelijk de buigpezen), maar kan ook het skelet, de gewrichten en zelfs het hoefkapsel beïnvloeden (Figuur 5 en 6).

Problemen met de zijdelingse hoefbalans veroorzaken compressie aan één kant van de interfalangeale gewrichten (Chateau et al., 2002), wat uiteindelijk kraakbeendegeneratie of beschadiging van het subchondrale bot in de hand kan werken. Daarnaast kan een afwijking van de mediolaterale hoefbalans resulteren in een progressieve vervorming van het hoornkapsel, zoals bijvoorbeeld een opgeschoven kroonrand of zogenaamde "sheared heels", en zelfs hoornscheuren. Wanneer een hoef visueel lijkt te landen op de laterale zijde, is het van groot belang om de hoogte van het mediale en laterale deel van de hoefwand te beoordelen. In dergelijke gevallen wordt meestal verondersteld dat de laterale zijde hoger is en ingekort dient te worden om een visueel vlakke landing te verkrijgen (Stashak et al., 2002). Met betrekking tot de voor-achterwaartse hoefbalans werd aangetoond dat een periode van acht weken tussen twee bekapsessies bij normale paarden resulteert in een significante stijging van het krachtmoment ter hoogte van het hoefgewricht (Moleman et al., 2006).

Het bekappen heeft als doel de hefboomwerking te verminderen en de zijdelingse en voor-achterwaartse hoefbalans te optimaliseren. In het geval van valgus- of varusdeformaties is het mogelijk om naast het correctief bekappen ook respectievelijk mediale of laterale extensies aan te brengen, maar overdreven aanpassingen moeten vermeden worden. Grote afwij- 


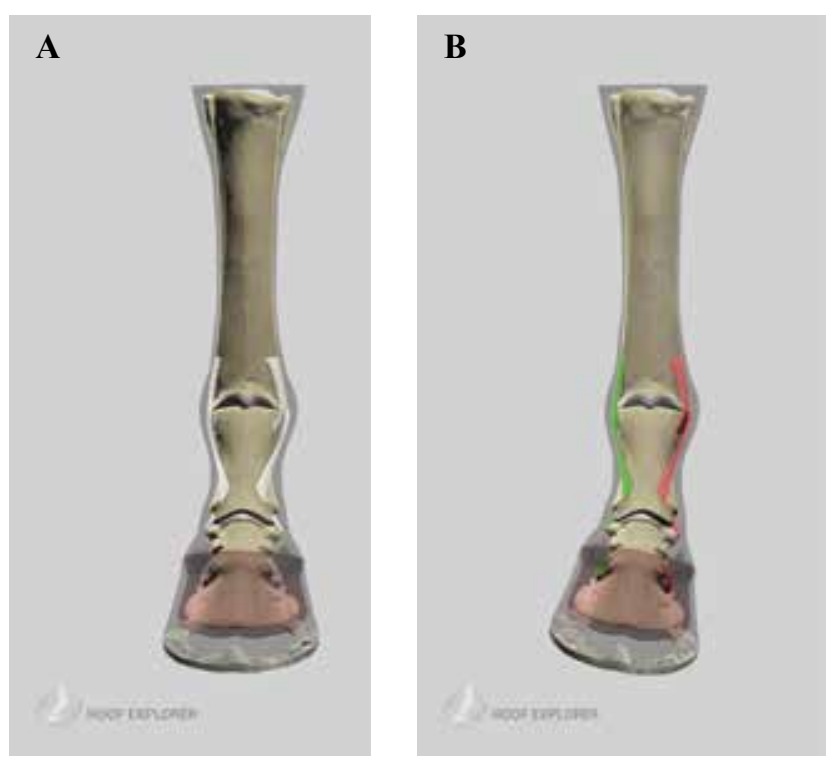

Figuur 7A. Distale deel van het lidmaat in voor-achterwaartse richting bekeken. B. Door het wegzakken van één zijde van de hoef te bevorderen door middel van een smallere tak van het hoefijzer, kan compressie ter hoogte van beschadigd kraakbeen of subchondraal bot aan die zijde verminderd worden. Tegelijkertijd kan het beperken van het wegzakken van de andere zijde van de hoef door middel van een bredere tak van het hoefijzer aangewezen zijn om spanning op ligamenten aan die zijde te beperken. (Beeldmateriaal uit Hoofexplorer.com met toestemming van Effigos AG, Deutscher Platz 4, 04103 Leipzig, Duitsland).

kingen in de hoefbalans worden het beste geleidelijk gecorrigeerd. Het correctief bekappen is van fundamenteel belang vooraleer eender welk type hoefijzer geplaatst wordt; het aanbrengen van hoefbeslag zonder voldoende aandacht te geven aan het bekappen is een gemiste kans (Parks, 2011b). Het breedste deel van het zooloppervlak van de hoef benadert het rotatiecentrum van het hoefgewricht. Op basis van dergelijke uitwendige kenmerken werden richtlijnen beschreven voor het bekappen en aanbrengen van hoefbeslag (O'Grady, 2009).

De hoefbalans heeft een direct effect op de intra-articulaire drukverdeling, waarbij een optimale hoefbalans resulteert in het grootste contactoppervlak tussen de gewrichtsvlakken in het hoefgewricht en bijgevolg ook in de laagste druk in dit gewricht (Viitanen et al., 2003). Op basis van grondig klinisch onderzoek en beeldvormingstechnieken, zoals echografie en MRI, "contrast-enhanced computed tomography" (CT), kan in sommige gevallen de exacte locatie aangetoond worden waar zich de kraakbeenletsels, de pathologie ter hoogte van het subchondrale bot of de wekedelenletsels bevinden. In het geval van een eenzijdig gecollabeerde gewrichtsinterlinie, bijvoorbeeld het mediale deel van het hoefgewricht, kan geprobeerd worden om de compressie aan de aangetaste zijde van het gewricht te verminderen door deze zijde verder te laten weg zakken in een zachte bodem. Dit kan ge- beuren door de tak van het hoefijzer aan de aangetaste zijde smaller te maken en aan de andere zijde de tak te verbreden. In geval van letsels ter hoogte van een collateraalband kan een breder oppervlak onder de aangetaste zijde gebruikt worden om de tractie op het aangetaste ligament te verminderen, althans op een zachte bodem (Parks, 2011b) (Figuur 7A en B). Empirisch wordt in de behandeling van osteoartritis van het distale deel van de sprong ("spat") en van intermitterende fixatie van de patella soms gebruik gemaakt van een hoefijzer met een bredere, laterale tak of zelfs van een laterale hielwig, in combinatie met het afronden van het mediale deel van de teenregio.

Zoals eerder aangehaald, kunnen ook in een voorachterwaartse richting aanpassingen uitgevoerd worden om de hielen minder diep of dieper te laten wegzakken in een zandbodem, bijvoorbeeld door gebruik te maken van respectievelijk een egg-bar-hoefijzer of een ijzer met een bredere teen en smallere takken (Chateau et al. 2006a; Oomen et al., 2012). Door het grotere contactoppervlak in respectievelijk de hiel- of teenregio zakt de hoef in dat gebied minder diep weg. Dit kan aangewezen zijn in het geval van tendinopathieën.

Een aangepaste drukverdeling kan ook overwogen worden in de behandeling van hoefbevangenheid, omdat een zool van geëxpandeerd polystyreen (piepschuim) het contactoppervlak vergroot, de druk verlaagt en in een achterwaartse verplaatsing van de drukverdeling resulteert (Schleining et al., 2011). Empirisch blijkt ook een "wooden shoe" met een sterke afronding gelijkaardige effecten te hebben, in combinatie met de verminderde stress bij breakover en de mogelijkheid om de hoek tussen het hoefbeen en de bodem aan te passen door het verhogen van de hielregio (O'Grady en Steward, 2009).

De traditionele visuele beoordeling van de dynamische hoefbalans lijdt onder de inherente beperkingen van het menselijke oog. Zelfs voor een ervaren clinicus kunnen subtiele afwijkingen onopgemerkt blijven, zeker bij gangen die sneller zijn dan de stap. Radiografisch onderzoek kan uitgevoerd worden om beslissingen te nemen tijdens het bekappen of aanbrengen van hoefbeslag, maar dit omhelst enkel een statische beoordeling en geeft bijgevolg geen informatie over de hoefbalans tijdens beweging. Voor het menselijke oog (10-15 beelden/seconde) lijkt een normale hoef initieel gelijktijdig contact te maken met de bodem met de mediale en laterale hiel en landen de hielen meestal vlak voor of simultaan met de teenregio. Kwantitatieve analyse heeft echter aangetoond dat laterale hiellanding zeer vaak voorkomt (Van Heel et al., 2004; Parks, 2011a). Recent onderzoek gebruikmakend van drukplaatanalyse heeft objectief en dynamisch inzicht verschaft in de teen-hiel- en mediolaterale hoefbalans van normale, gezonde sportpaarden in stap en in draf op een harde bodem en van normale, gezonde pony's in stap en in draf op een zandbodem (Oosterlinck et al., 2013, 2014). In tegenstelling tot 
A

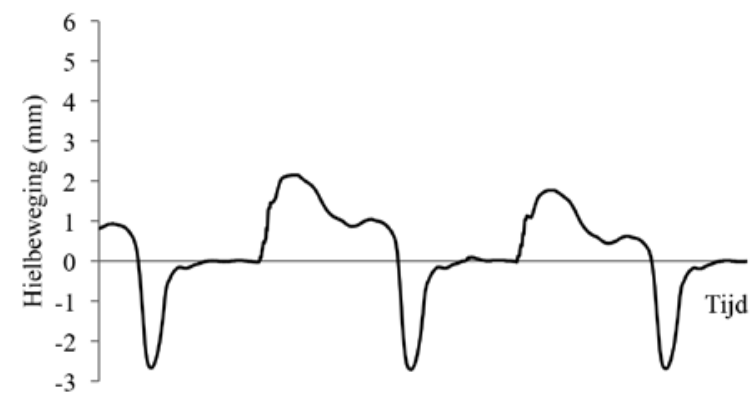

B

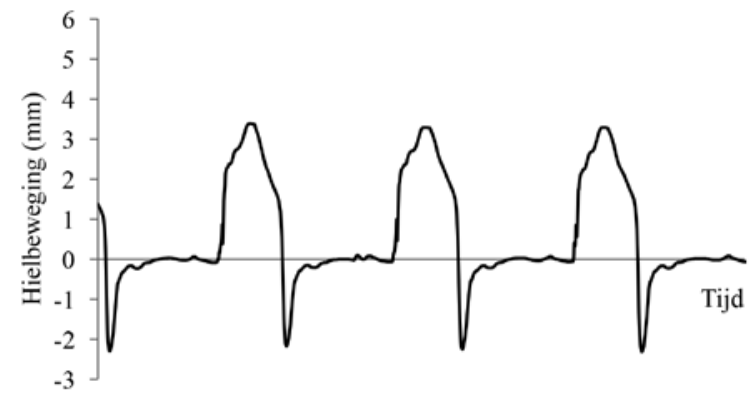

C

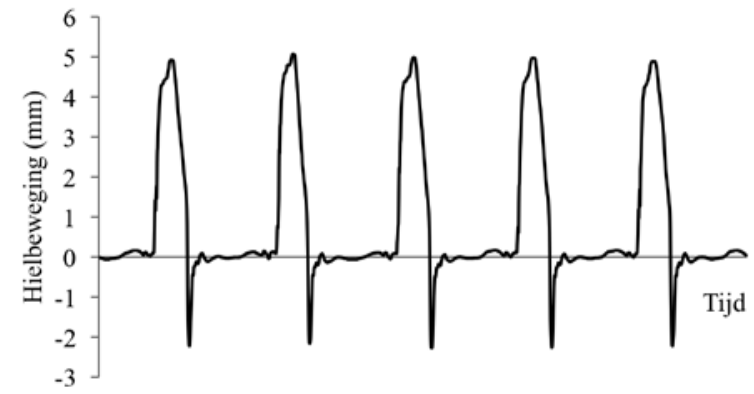

Figuur 8. Hielbeweging A. in stap, B. draf en C. galop bij een onbeslagen paard. Positieve waarden wijzen op hielexpansie, negatieve waarden op hielcontractie.

wat vaak verondersteld wordt, is aangetoond dat de belasting bij normale hoeven die visueel vlak/symmetrisch lijken te landen, niet gelijk verdeeld is en de laterale zijde zwaarder belast wordt (Oosterlinck et al., 2013). De verdere ontwikkeling van deze toepassing van biomechanische analyse van de hoefbalans kan in de toekomst leiden tot objectief en kwantitatief advies met betrekking tot het bekappen van hoeven en het aanbrengen van specifiek hoefbeslag, net zoals heden ten dage met sportschoenen en inlegzolen bij de mens gebeurt.

Het hoornkapsel van de hoef verschaft goede schokdemping, wat ervoor zorgt dat er weinig tot geen vibraties worden doorgegeven tot boven het kogelgewricht. Hoefbeslag vermindert het schokdempend vermogen van de hoef. Het effect is echter verschillend naargelang het materiaal waaruit het hoefijzer is gemaakt: het schokdempend vermogen van staal is kleiner dan dat van aluminium, dat op zijn beurt kleiner is dan dat van kunststoffen hoefijzers, terwijl visco-elastische zooltjes met of zonder opvulling tus- sen de hoef en het zooltje dit effect verder kunnen versterken (Back et al., 2006; Back en Pille, 2013). Dit aspect kan bijvoorbeeld nuttig zijn in de behandeling van letsels ter hoogte van subchondraal bot of andere vormen van osteoartritis.

Het is belangrijk om te beseffen dat het glijden van de hoef een normaal fenomeen is gedurende de secundaire impactfase. De mate van doorglijden is sterk afhankelijk van het type bodem, de snelheid en vele andere factoren. De beperkte mate van beweging in horizontale richting gedurende het afremmen laat dissipatie van energie toe en vermindert dus de grootte van de belasting en de snelheid waarmee ze opgebouwd wordt. Er is uiteraard slechts een beperkte marge: te veel doorglijden resulteert in instabiliteit en risico op valpartijen; te weinig glijden en energiedissipatie zorgen voor een enorme opstapeling van energie in het skelet en de weke delen, en vergroten de kans op breuken en andere letsels. Indien extra grip vereist is voor sportieve prestaties kunnen in de plaats van het gebruik van kalkoenen andere, meer subtiele maatregelen genomen worden om grip te verhogen, zoals widiapunten, hoefijzers met een rits over de hele lengte, het concaaf maken van de onderzijde van het hoefijzer, etc.

Er zijn verschillende methoden die van oudsher empirisch toegepast worden om breakover te bevorderen, wat nuttig kan zijn in geval van osteoartritis, problemen in het hoefkatrolgebied, hoefbevangenheid en bij verschillende wekedelenletsels. Een hoefijzer met een hielwig vermindert de duur van de breakover-fase in vergelijking met een normaal, vlak ijzer en in vergelijking met een egg-bar-hoefijzer (Rogers en Back, 2007). Daarenboven reduceert hoefbeslag met hielwig de maximale kracht die uitgeoefend wordt op het straalbeen met 24\% (Willemen et al., 1999). De keuze tussen een ijzer met vierkante teen, een ijzer dat extra teruggepast wordt, een omgekeerd ijzer, een afgeronde teen ("rolling toe"), een "rocker-toe", een "natural balance" teen, etc. of een combinatie van deze principes is vooral afhankelijk van de individuele voorkeur van de behandelende dierenarts. Er zijn verschillende meningen omtrent het principe van de afgeronde teen (Johnston en Back, 2006). Algemeen worden hoefijzers met de hierboven vermelde aanpassingen gebruikt om de momentarm van de verticale kracht ter hoogte van het hoefgewricht te verkorten (Eliashar et al., 2002). Het effect ervan speelt echter enkel mee nadat de hielen de bodem hebben verlaten en wanneer dus de verticale kracht reeds substantieel verminderd is. Aangezien het maximale krachtmoment ter hoogte van het hoefgewricht reeds bereikt wordt vooraleer de hielen de bodem verlaten, zouden dergelijke aanpassingen geen effect hebben op de maximale belasting van de diepe buigpees (Eliashar et al., 2002; Buchner, 2005). Niettegenstaande werd aangetoond dat het afrolpatroon van de hoef geleidelijker verloopt en dat er op een harde bodem minder piekbelasting en stress op het distale deel van het lidmaat uitgeoefend 
worden (van Heel et al., 2006; Spaak et al., 2013). Zoals reeds eerder vermeld, ondervindt een onbeslagen paard $14 \%$ minder belasting ter hoogte van het straalbeen dan een paard met een normaal, vlak beslag, wat op zich al therapeutisch interessant kan zijn (Willemen et al., 1999).

Een laatste belangrijk aspect van de biomechanica van de hoef is het zogenaamde hoefmechanisme. Dit is de deformatie die de hoef ondergaat tijdens de beweging van het paard. Deze deformatie wordt belangrijk geacht voor schokabsorptie, namelijk het dissiperen van energie die gecreëerd wordt tijdens impact (Pollit, 1992; Dyhre-Poulsen et al., 1994). Het hoefmechanisme zorgt verder voor het pompen van bloed in de hoef, wat de bloedcirculatie in de hoef, de hoorngroei en hoornkwaliteit positief beïnvloedt (Ratzlaff et al., 1985).

Het hoefmechanisme werd onder meer bestudeerd door middel van rekstrookjes (Dyhre-Poulsen et al., 1994; Thomason, 1998; Thomason et al., 2001, 2002; Roepstorff et al., 2001); foto-elastisch materiaal (Davies, 1996; Dejardin et al., 2001), optische systemen (Roepstorff et al. 2001), verplaatsingssensoren (Roepstorff et al. 2001; Yoshihara et al., 2010), doppler (Pietra et al., 2004), speciale hoefschoenen (Barrey, 1990), digitale fotografie (Hinterhofer et al., 2006) en wiskundige computermodellen ("finite element analysis") (Hinterhofer et al., 1997; 2000; 2001; Thomason et al., 2002). Ondanks het feit dat door de specifieke meetmethoden in deze studies verschillende aspecten van hoefdeformatie werden beschreven en hier en daar variaties en kleine tegenstrijdigheden gerapporteerd werden, is men het eens over de belangrijkste facetten van hoefdeformatie. Tijdens het steunen vertonen de zool en straal een neerwaartse beweging (Hinterhofer et al., 2000) en wijkt het proximale deel van de dorsale hoefwand achteruit (Thomason, 1998). De belangrijkste deformatie vindt plaats ter hoogte van de hielen, doordat de hielregio van de hoef het meest elastisch is en de mechanische belasting het grootst is in de caudale regio van de hoef (Barrey, 1990; Douglas et al., 1998). Onder invloed van de verticale grondreactiekracht in de caudale regio van de hoef en de druk ter hoogte van de straalregio wijken de hielen uit elkaar (Colles, 1989; Kai et al., 2000). In een andere theorie wordt gesteld dat deze hielexpansie plaatsvindt ten gevolge van het zakken en achteruit kantelen van het kroonbeen dat zo de hielen uit elkaar duwt (Dyhre-Poulsen et al., 1994). Roepstorff et al. (2001) ondersteunen beide theorieën en toonden verder aan dat hielexpansie enkel optreedt tijdens de eerste $70-80 \%$ van de steunfase. In een tweede fase, tijdens de breakover, werd in die studie een contractie van de hielen gezien. Een directe verklaring voor dit fenomeen is er niet maar moet gezocht worden in de driedimensionale vervorming van het hoornkapsel ten gevolge van de stijgende grondreactiekracht in de teenregio tijdens de breakover (Roepstorff et al., 2001). Yoshihara et al. (2010), die ditzelfde patroon van hielbeweging hebben vastgesteld, suggereren dat hielcontractie tot stand wordt gebracht door de ligamenten en het bindweefsel die het hoefkraakbeen verbinden met het hoefbeen, kroonbeen en kootbeen. De voorwaartse rotatie van het kroonbeen zorgt via de ligamenten en het hoefkraakbeen voor de rotatie van de hoef, voor het opheffen en tenslotte de contractie van de hielen.

De mate van hielexpansie stijgt bij hogere snelheden, aangezien de verticale grondreactiekracht stijgt naargelang de snelheid van de beweging verhoogt. Hielcontractie daarentegen blijft vrijwel constant bij alle snelheden waarschijnlijk omdat de verticale grondreactiekracht ter hoogte van de teen tijdens de breakover nagenoeg dezelfde blijft ongeacht de snelheid (Yoshihara et al., 2010).

Door middel van een hoogfrequente verplaatsingssensor $(800 \mathrm{~Hz})$ (AE Sensors, Dordrecht, Nederland) werd door de onderzoeksgroep van de auteurs recentelijk eenzelfde patroon van hielexpansie en hielcontractie bij verschillende snelheden vastgesteld (Figuur 8).

De hielbeweging wordt beïnvloed door de geometrie van de hoef. Paarden met steile en nauwe hielen, uitgesproken steunsels en een smalle straal vertonen minder hielexpansie dan paarden met lage hielen, weinig ontwikkelde steunsels en een brede straal. Steilere hoeven zijn dus 'stijver' en vertonen minder schokabsorptie tijdens impact (Thomason et al., 1998).

Het aanbrengen van hoefbeslag limiteert de mediolaterale hielbeweging (Hinterhofer et al., 2001; Roepstorff et al., 2001). Het experimentele verhogen van druk ter hoogte van de zool en straal door middel van een opblaasbaar kussen, zorgde in een studie van Roepstorff et al. (2001) daarentegen voor een significante toename van hielexpansie. Echter, zelfs als de straal niet in contact kwam met de grond, trad er nog hielexpansie op (Roepstorff et al., 2001), wat suggereert dat ook andere mechanismen dan druk ter hoogte van de straal verantwoordelijk zijn voor het hoefmechanisme. Yoshihara et al. (2010) toonden aan dat het lijmen van hoefschoenen de hielexpansie niet limiteert ten opzichte van het nagelen van een ijzer ter hoogte van de voorhoeven maar wel ter hoogte van de achterhoeven. Hielcontractie daarentegen werd significant meer gelimiteerd door het lijmen van een ijzer op de hoef dan wanneer het werd genageld en dit zowel ter hoogte van de voor- als achterhoeven (Yoshihara et al., 2010). Recent werd door de onderzoeksgroep van de auteurs aangetoond dat een hoefijzer dat bestaat uit twee afzonderlijke delen, i.e. het moerman-hoefijzer, een vergelijkbare mate van hielbeweging toelaat als een onbeslagen hoef, terwijl een conventioneel hoefijzer het hoefmechanisme significant belemmert (Brunsting et al., 2016).

In sommige gevallen is het limiteren van het hoefmechanisme gewenst, zoals tijdens de behandeling van hoefbeenfracturen. Het typische hoefbeslag dat gebruikt wordt bij de behandeling van deze letsels, 
namelijk een balkijzer met een teenlip en extra zijlippen die achter het derde nagelgat worden geplaatst, minimaliseert effectief het hoefmechanisme (Hinterhofer et al., 2001). Door sommigen wordt dit gecombineerd met een zooltje en silicone-opvulling om vernauwing van de hielen tegen te gaan en om ondersteuning te bieden aan het hoefbeen (O'Grady, 2011). Een alternatief voor het hoefijzer met extra zijlippen is het gebruik van een hoefijzer met een volledige rand die de draagrand omvat of het aanbrengen van een synthetisch gipsverband rechtsreeks op de hoornwand (O'Grady, 2011). Ook het vergroten van de hielhoek met $5^{\circ}$ veroorzaakt significant minder hoefdeformatie (Hinterhofer et al., 2000).

\section{CONCLUSIE}

Er is vrij veel biomechanische informatie beschikbaar die nuttige aanwijzingen kan verschaffen voor het "evidence-based" bekappen en/of aanbrengen van hoefbeslag. De laatste jaren gebeurt bovendien meer en meer onderzoek naar het biomechanische effect van de samenstelling en het onderhoud van de bodem waarop paarden presteren (Thomason en Peterson, 2008). Gecontroleerde studies van het bekappen en/of hoefbeslag voor specifieke oorzaken van kreupelheid zijn tot nog toe echter niet beschikbaar.

Elk advies met betrekking tot het bekappen of aanbrengen van hoefbeslag moet gebaseerd zijn op de grondige beoordeling van de statische en dynamische hoefbalans en op een volledig bewegings/ kreupelheidsonderzoek van de individuele patiënt. Bovendien moet het advies geformuleerd worden in functie van de specifieke vereisten van de sportdiscipline waarvoor het paard gebruikt wordt. Op basis van de biomechanische aspecten van hoefbelasting kan bij aanpassingen qua bekappen of hoefbeslag in de behandeling van kreupelheid de nadruk gelegd worden op optimale hoefbalans, absorptie van schokken, gepaste mate van grip/afremmen versus glijden, optimale drukverdeling binnen de hoef, en het bevorderen van de breakover. Ook met de invloed van bijvoorbeeld het hoefbeslag op het hoefmechanisme moet rekening gehouden worden. Idealiter worden de meeste van deze principes gecombineerd in de preventie van letsels.

\section{REFERENTIES}

Back W., Pille F. (2013). The role of the hoof and shoeing. In: Back W., Clayton H.M. (editors). Equine Locomotion. Tweede editie, W.B. Saunders, Elsevier, London, p. 147-174.

Back W., Schamhardt H.C., Hartman W., Barneveld A. (1995). Kinematic differences between the distal portions of the forelimbs and hindlimbs of horses at the trot. American Journal of Veterinary Research 56, 1522-1528. Back W., Van Schie M.H.M., Pol J.N. (2006). Synthetic shoes attenuate hoof impact in the trotting warmblood horse. Equine and Comparative Exercise Physiology 3, 143-151.

Barrey E. (1990). Investigation of the vertical hoof force distribution in the equine forelimb with an instrumented horseboot. Equine Veterinary Journal 22 Supplement 9 , 35-38.

Brunsting J., Dumoulin M., Haspeslagh M., Oosterlinck M., Pille F. (2016). Can the hoof be shod without limiting the hoof mechanism? Veterinary Surgery 45, E8.

Buchner H.H.F. (2005). Distal limb internal dynamics: joint moments, tendon forces, and lessons for orthopedic shoeing. In: Proceedings 51 st Annual Convention of the American Association of Equine Practitioners. Seattle, Washington, p. 134-140.

Chateau H., Degueurce C., Denoix J.M. (2004). Effects of $6^{\circ}$ elevation of the heels on 3D kinematics of the distal portion of the forelimb in the walking horse. Equine Veterinary Journal 36, 649-654.

Chateau H., Degueurce C., Denoix J.M. (2006a). Effects of egg-bar shoes on the 3-dimensional kinematics of the distal forelimb in horses walking on a sand track. Equine Veterinary Journal 38 Supplement 36, 377-382.

Chateau H., Degueurce C., Denoix J.M. (2006b). Threedimensional kinematics of the distal forelimb in horses trotting on a treadmill and effects of elevation of heel and toe. Equine Veterinary Journal 38, 164-169.

Chateau H., Degueurce C., Jerbi H., Crevier-Denoix N., Pourcelot P., Audigié F., Pasqui-Boutard V., Denoix J.M. (2002). Three-dimensional kinematics of the equine interphalangeal joints: articular impact of asymmetric bearing. Veterinary Research 33, 371-382.

Colles C.M. (1989). The relationship of frog pressure to heel expansion. Equine Veterinary Journal 21, 13-16.

Davies H.M.S. (1996). A technical report on redistribution of strain in the hoof wall of a standing horse before and after trimming. Pferdeheilkunde 12, 679-680.

Degueurce C., Chateau H., Jerbi H., Crebier-Denoix N., Pourcelot P., Audigié F., Pasqui-Boutard V., Geiger D., Denoix J.M. (2001). Three-dimensional kinematics of the proximal interphalangeal joint: effect of raising the heels or toe. Equine Veterinary Journal 33 Supplement 33, 79-83.

Dejardin L.M., Arnoczky S.P., Cloud G.L., Stick J.A. (2001). Photoelastic stress analysis of strain patterns in equine hooves after four-point trimming. American Journal of Veterinary Research 62, 467-473.

Douglas J.E., Biddick T.L., Thomasson J.J., Jofriet J.C. (1998). Stress/strain behaviour of the equine laminar junction. Journal of Experimental Biology 201, 22872297.

Dyhre-Poulsen P., Smedegaard H.H., Roed J., Korsgaard E. (1994). Equine hoof function investigated by pressure transducers inside the hoof and accelerometers mounted on the first phalanx. Equine Veterinary Journal 26, 326366.

Eliashar E. (2007). An evidence-based assessment of the biomechanical effects of the common shoeing and farriery techniques. Veterinary Clinics of North America Equine Practice 23, 425-442.

Eliashar E., McGuigan M.P., Rogers K.A., Wilson A.M. (2002). A comparison of three horseshoeing styles on the kinetics of breakover in sound horses. Equine Veterinary Journal 34, 184-190.

Gustas P., Johnston C., Hedenström U., Roepstroff L., Dre- 
vemo S. (2006). A field study on hoof deceleration at impact in Standardbred trotters at various speeds. Equine and Comparative Exercise Physiology 3, 161-168.

Hagen J., Hüppler M., Häfner F., Geiger S., Mäder D. (2016). Modifying horseshoes in the mediolateral plane: Effects of side wedge, wide branch, and unilateral roller shoes on the phalangeal alignment, pressure forces, and the footing pattern. Journal of Equine Veterinary Science $37,77-85$.

Hagen J., Hüppler M., Geiger S.M., Mäder D., Häfner F.S. (2017). Modifying the height of horseshoes: Effects of wedge shoes, studs, and rocker shoes on the phalangeal alignment, pressure distribution, and hoof-ground contact during motion. Journal of Equine Veterinary Science $53,8-18$.

Hinterhofer C., Stanek C., Haider H. (1997). Simulation of pressure by means of a finite element computer model of the equine hoof capsule. Pferdeheilkunde 13, 319-328.

Hinterhofer C., Stanek C., Haider H. (2000). The effect of flat horseshoes, raised heels and lowered heels on the biomechanics of the equine hoof assessed by finite element analysis (FEA). Journal of Veterinary Medicine. A, Physiology, Pathology, Clinical Medicine 47, 73-82.

Hinterhofer C., Stanek C., Haider H. (2001). Finite element analysis (FEA) as a model to predict effects of farriery on the equine hoof. Equine Veterinary Journal 33 Supplement 33, 58-62.

Hinterhofer C., Weißbacher N., Buchner H.H.F., Peham C., Stanek C. (2006). Motion analysis of hoof wall, sole and frog under cyclic load in vitro: deformation of the equine hoof shod with regular horse shoe, straight bar shoe and bare hoof. Pferdeheilkunde 22, 314-319.

Hüppler M., Häfner F., Geiger S., Mäder D., Hagen J. (2016). Modifying the surface of horseshoes: Effects of eggbar, heartbar, open toe, and wide toe shoes on the phalangeal alignment, pressure distribution, and the footing pattern. Journal of Equine Veterinary Science 37, 86-97.

Johnston C., Back W. (2006). Hoof ground interaction: when biomechanical stimuli challenge the tissues of the distal limb. Equine Veterinary Journal 38, 634-641.

Kai M., Aoki O., Hiraga A., Oki H., Oki H., Tokuriki M. (2000). Use of an instrument sandwiched between the hoof and shoe to measure vertical ground reaction forces and three-dimensional acceleration at the walk, trot, and canter in horses. American Journal of Veterinary Research 61, 979-985.

Lawson S.E.M., Chateau H., Pourcelot P., Denoix J.M., Crevier-Denoix N. (2007). Effect of toe and heel elevation on calculated tendon strains in the horse and the influence of the proximal interphalangeal joint. Journal of Anatomy 210, 583-591.

Martens A., Levet T., Saunders J., Pille F. (2008). Beoordeling en behandeling van valgus- en varusdeviaties bij het veulen. Vlaams Diergeneeskundig Tijdschrift 78, 113118.

Moleman M., Van Heel M.C.V., Van Weeren P.R., Back W. (2006). Hoof growth between two shoeing sessions leads to a substantial increase of the moment about the distal, but not the proximal, interphalangeal joint. Equine Veterinary Journal 38, 170-174.

O'Grady S.E. (2009). Guidelines for trimming the equine foot: a review. In: Proceedings $55^{\text {th }}$ Annual Convention of the American Association of Equine Practitioners. Las Vegas, Nevada, p. 218-225.

O'Grady S.E., Steward M. (2009). The wooden shoe as an option for treating chronic laminitis? Equine Veterinary Education 8, 272-276.

O'Grady S.E. (2011). Farriery for common hoof problems. In: Baxter, G.M. (editor). Adams and Stashak's Lameness in Horses. Zesde editie, Wiley Blackwell, West Sussex, p. 1199-1210.

Oomen A.M., Oosterlinck M., Pille F., Sonneveld D.C., Gasthuys F., Back W. (2012). Use of a pressure plate to analyse the toe-heel load redistribution underneath a shoe with a normal toe and a shoe with a wide toe in sound warmblood horses at the walk and trot. Research in Veterinary Science 93, 1026-1031.

Oosterlinck M., Hardeman L.C., van der Meij B.R., Veraa S., van der Kolk J.H., Wijnberg I.D., Pille F., Back W. (2013). Pressure plate analysis of toe-heel and medio-lateral hoof balance at the walk and trot in sound sport horses. The Veterinary Journal 198, Supplement 1, e9-e13.

Oosterlinck M., Pille F., Back W., Dewulf J., Gasthuys F. (2010). Use of a stand-alone pressure plate for the objective evaluation of forelimb symmetry in sound ponies at walk and trot. The Veterinary Journal 183, 305-309.

Oosterlinck M., Pille F., Back W., Dewulf J., Gasthuys F. (2011). A pressure plate study on fore and hindlimb loading and the association with hoof contact area in sound ponies at the walk and trot. The Veterinary Journal 190, 71-76.

Oosterlinck M., Pille F., Dumoulin M., Gasthuys F. (2007). Moderne technieken voor kreupelheidsonderzoek bij het paard: beter dan de klinische blik? Vlaams Diergeneeskundig Tijdschrift 76, 91-102.

Oosterlinck M., Royaux E., Back W., Pille F. (2014). A preliminary study on pressure plate evaluation of forelimb toe-heel and medio-lateral hoof balance on a hard versus a soft surface in sound ponies at the walk and trot. Equine Veterinary Journal 46, 751-755.

Oosterlinck M., Van der Aa R., Van de Water E., Pille F. (2015). Preliminary evaluation of toe-heel and mediolateral hoof balance at the walk in sound horses with toedin hoof conformation. Journal of Equine Veterinary Science 35, 606-610.

Parks A.H. (2003). Form and function of the equine digit. Veterinary Clinics of North America Equine Practice 19, 285-307.

Parks A.H. (2011a). The foot and shoeing. In: Ross M.W., Dyson S.J. (editors). Diagnosis and Management of Lameness in the Horse. Tweede editie, Saunders, St Louis, Missouri, p. 282-309.

Parks A. (2011b). Therapeutic trimming and shoeing. In: Baxter, G.M. (editor). Adams and Stashak's Lameness in Horses. Zesde editie, Wiley Blackwell, West Sussex, p. 986-995.

Pietra M., Guglielmini C., Nardi S., Gandini G., Cipone M. (2004). Influence of weight bearing and hoof position on Doppler evaluation of lateral palmar digital arteries in healthy horses. American Journal of Veterinary Research 65, 211-2015.

Pollitt, C.C. (1992). Clinical anatomy and physiology of the normal equine foot. Equine Veterinary Education 4, 219-224.

Ratzlaff M.H., Shindell R.M., Debowes R.M. (1985). Changes in digital venous pressures of horses moving at the walk and trot. American Journal of Veterinary Research 46, 1545-1549.

Rogers C.W., Back W. (2007). The effect of plain, eggbar and $6^{\circ}$-wedge whose on the distribution of pressure un- 
der the hoof of horses at the walk. New Zealand Veterinary Journal 55, 120-124.

Roepstorff L., Johnston C., Drevemo S. (2001). In vivo and in vitro heel expansion in relation to shoeing and frog pressure. Equine Veterinary Journal 33 Supplement 33, 54-57.

Roepstorff L. (2012). The development of clinical tools based on biomechanical research. The Veterinary Journal 192, 129-130.

Schleining J.A., McClure, S.R., Derrick T.R., Wang C. (2011). Effects of industrial polystyrene foam insulation pads on the center of pressure and load distribution in the forefeet of clinically normal horses. American Journal of Veterinary Research 72, 628-633.

Spaak B., Van Heel M.C.V., Back W. (2013). Toe modifications in hind feet shoes optimise hoof-unrollment in sound Warmblood horses at trot. Equine Veterinary Journal 45, 485-489.

Stashak T.S., Hill C., Klimesh R., Ovnicek G. (2002). Trimming and shoeing for balance and soundness. In: Stashak T.S. (editor). Adams'Lameness in Horses. Vijfde editie, Lippincott Williams \& Wilkins Philadelphia, p. 1081-1144.

Thomason J.J. (1998). Variation in surface strain on the equine hoofwall at the midstep with shoeing, gait, substrate, direction of travel, and hoof angle. Equine Veterinary Journal 30 Supplement 26, 86-95.

Thomason J.J., Bignell W.W., Sears W. (2001). Components of variation of surface hoof strain with time. Equine Veterinary Journal 33 Supplement 33, 63-66.

Thomason J.J., McClinchey H.L., Jofriet J.C. (2002). Analysis of strain and stress in the equine hoof capsule using finite element methods: comparison with principal strains recorded in vivo. Equine Veterinary Journal 34, 719-725.

Thomason J.T., Peterson M.L. (2008). Biomechanical and mechanical investigations of the hoof-track interface in racing horses. Veterinary Clinics of North America Equine Practice 24, 53-77.

Van Heel M.C.V., Barneveld A., Van Weeren P.R., Back W. (2004). Dynamic pressure measurements for the detailed study of hoof balance: the effect of trimming. Equine Veterinary Journal 36, 778-782.

Van Heel M.C.V., Van Weeren P.R., Back W. (2006). Shoeing sound Warmblood horses with a rolled toe optimizes hoof-unrollment and lowers peak loading during breakover. Equine Veterinary Journal 38, 258-262.

Viitanen M.J., Wilson A.M., McGuigan H.P., Rogers K.D., May S.A. (2003). Effect of foot balance on the intra-articular pressure in the distal interphalangeal join in vitro. Equine Veterinary Journal 35, 184-189.

Willemen M.A., Savelberg H.H.C.M., Barneveld A. (1999). The effect of orthopaedic shoeing on the force exerted by the deep digital flexor tendon on the navicular bone in horses. Equine Veterinary Journal 31, 25-30.

Wilson A.M., Seelig T.J., Shield R.A., Silverman B.W. (1998). The effect of foot imbalance on point of force application in the horse. Equine Veterinary Journal 30, 540-545.

Yoshihara E., Takahashi T., Otsuka N., Isayama T., Hiraga A., Wada S. (2010). Heel movement in horses: comparison between glued and nailed horse shoes at different speeds. Equine Veterinary Journal 42 Supplement 38, 431-435. 